\title{
Non-gonococcal urethritis due to T-mycoplasma (Ureaplasma urealyticum) serotype 2 in a conjugal sexual partnership
}

\author{
D. K. FORD AND E. HENDERSON \\ Department of Medicine, Vancouver General Hospital, and the University of British Columbia Faculty of Medicine, \\ Vancouver, B.C., Canada
}

\section{Introduction}

The importance of T-mycoplasma (Ureaplasma urealyticum) in the aetiology of non-gonococcal urethritis is under continued investigation and discussion. The following clinical study suggests a causative role in the recurrent urethritis suffered by the husband of one conjugal sexual partnership, and it supports a recent case report (Ford and Smith, 1974) that $T$-mycoplasmas can, in at least specific circumstances, cause urethritis.

\section{Case report}

A man aged 50 years was referred to one of us (DKF) in October, 1974, for recurrent non-gonococcal urethritis. He stated that he had suffered from many attacks of urethritis during his 25 years of marriage and had contracted an episode after virtually every sexual intercourse with his wife. He had never complained of definite arthritis in association with his urethritis, though he had noted some arthralgia on occasions and thought that his eyes were sometimes reddened during the bouts of urethritis. He had been treated with both tetracycline and erythromycin at different times and both antibiotics seemed to stop the urethritis. On the occasion of this first visit he had a slight urethral discharge and he was given tetracycline $500 \mathrm{mg}$ four times a day for 10 days ; 2 weeks later his urethritis had cleared.

His wife a woman aged 46 , had noted slight intermittent vaginal discharge during her 25 years of married life; this minimal symptom had never been associated with dysuria or vulval soreness and she described herself as being in good health. She had been given both tetracycline and erythromycin in the past, on account of her husband's recurrent urethritis, but each of these drugs had caused side-effects, so that she had stopped each of them after only a few days.

In the summer of 1975 arrangements were made to study these conjugal partners in detail, the mycoplasmal investigations being performed in Vancouver and the chlamydial investigations in Seattle through co-operation with Drs K. K. Holmes, W. Bowie, E. R. Alexander, and S. P. Wang of the Department of Medicine and School of Public Health at the University of Washington.

Address for reprints: Dr. D. K. Ford, M.D., Division of Rheumatology, 700 West 10th Avenue, Vancouver, B.C., Canada
When he was seen again early in September, 1975, the husband was once more on tetracycline therapy for his third episode of urethritis in the preceding 3 months. His wife had had a total hysterectomy in May after abnormal cytology findings and she had subsequently been in good health. Examination confirmed the total hysterectomy. The 3-month-old suture line in the vaginal vault was healthy and there was no evidence of vaginitis or urethritis on careful clinical examination.

Cultures for $T$-mycoplasmas and chlamydiae were obtained from both patients over the following 2 months. The findings are shown in the Table.

TABLE Sequence of symptoms, treatment and cultures in a husband and wife

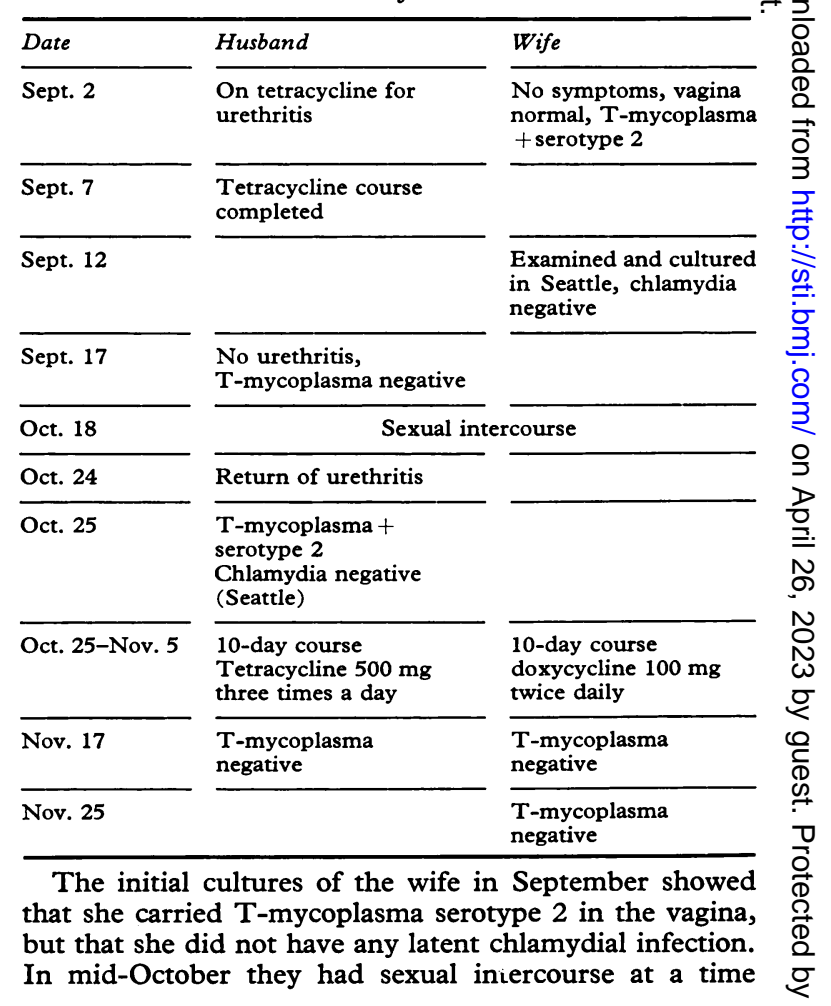


when the husband was asymptomatic and free of Tmycoplasmas, but 5 days later he again complained of symptoms of urethritis and had an obvious mucopurulent discharge, his fourth episode since May. A urethral culture in Vancouver grew T-mycoplasma serotype 2, but a culture in Seattle on the same day revealed no chlamydiae. Both were then treated with anti-T-mycoplasmal antibiotics, the man with tetracycline $500 \mathrm{mg}$ three times a day for 10 days and the woman with doxycycline $100 \mathrm{mg}$ twice daily for 10 days, which she could tolerate without side-effects. The urethritis in the man promptly disappeared and his urethral culture after completing the tetracycline course was negative for T-mycoplasma; the vagina of the woman was cultured twice and on both occasions was negative for T-mycoplasmas. At this point they were encouraged to have repeated sexual intercourse, which they did, but this was not associated with any recurrence of urethritis in the husband.

Blood samples were obtained for serum antibody studies on September 17 from the husband and again on November 17, 3 weeks after his October episode of urethritis. The Metabolic Inhibition Test (MIT) of Purcell (Purcell, Taylor-Robinson, Wong and Chanock, 1966) was used and negligible antibody (titre $<1: 4$ ) was found in both of these serum samples, even though the organism used for the test was that derived from the couple. This finding contrasts with titres of $1: 4$ or more in 30 per cent. of male patients attending the Vancouver Venereal Disease Control Clinic with a variety of different diagnoses.

Since both partners were treated in October, 1975, they have had repeated sexual intercourse and the husband has had no further episode of urethritis.

\section{Comment}

There would seem to be no reasonable doubt that T-mycoplasma serotype 2 was the cause of the recurrent urethritis. The Seattle group is extremely experienced in handling chlamydia and the cultures from the wife at the onset of the study, and of the husband when he developed urethritis during the study, were taken in Seattle by members of their team, but both were negative for chlamydia. The presence and absence of T-mycoplasma serotype 2 in the husband correlated precisely with the presence and absence of urethritis. The response of the urethritis to tetracycline indicated a tetracycline sensitive organism. He had four episodes of urethritis between May and October and each arose within a week of every intercourse with his wife. After the eradication of the T-mycoplasma from the wife, repeated intercourse was not associated with urethritis. The serological data is interesting and it would seem clear that this man did not develop metabolic inhibiting antibody to T-mycoplasma serotype 2 in spite of multiple urethral infections. The failure to develop humoral immunity might have been associated with his susceptibility to such infections; alternatively serum antibody might not normally develop in response to such infections. Currently no data is available to support any hypothesis and T-mycoplasma antibody responses to genital infections are not yet defined. It is noteworthy that, once the wife was treated with an antibiotic which she could tolerate for 10 days, the organism was eradicated.

The authors wish to thank Drs. E. R. Alexander, W. Bowie, K. K. Holmes, and S. P. Wang of the University of Washington, Seattle, for their help in this study.

\section{References}

Ford, D. K., and SMITH, J. R. (1974) Brit. F. vener. Dis., 50, 373

Purcell, R. H., Taylor-Robinson, D., Wong, D., and ChaNoCK, R. M. (1966) Э. Bact., 92, 6 